\title{
Acknowledgement to Reviewers of the Journal of Risk and Financial Management in 2016
}

\author{
JRFM Editorial Office \\ Published: 10 January 2017 \\ MDPI AG, St. Alban-Anlage 66, 4052 Basel, Switzerland; jrfm@mdpi.com
}

The editors of the Journal of Risk and Financial Management would like to express their sincere gratitude to the following reviewers for assessing manuscripts in 2016.

We greatly appreciate the contribution of expert reviewers, which is crucial to the journal's editorial process. We aim to recognize reviewer contributions through several mechanisms, of which the annual publication of reviewer names is one. Reviewers receive a voucher entitling them to a discount on their next MDPI publication and can download a certificate of recognition directly from our submission system. Additionally, reviewers can sign up to the service Publons (https://publons.com) to receive recognition. Of course, in these initiatives we are careful not to compromise reviewer confidentiality. Many reviewers see their work as a voluntary and often unseen part of their role as researchers. We are grateful to the time reviewers donate to our journals and the contribution they make.

If you are interested in becoming a reviewer for Journal of Risk and Financial Management, see the link at the bottom of the webpage http://www.mdpi.com/reviewers.

The following reviewed for Journal of Risk and Financial Management in 2016:

\author{
Aas, Kjersti \\ Bao, Jack \\ Barbi, Massimiliano \\ Barone Adesi, Giovanni \\ Baur, Dirk \\ Boubaker, Sabri \\ Brownlees, Christian T. \\ Caporin, Massimiliano \\ Cayón Fallón, Edgardo \\ Chang, Chia-Lin \\ Chen, James M. \\ Cui, Zhenyu \\ Czado, Claudia \\ Dentcheva, Darinka \\ Doronzo, Michele \\ Eling, Martin \\ Erdemlioglu, Deniz \\ Fábián, Csaba I. \\ Farkas, Erich Walter \\ Fermanian, Jean-David \\ Fillat, José L. \\ Gan, Christopher \\ Gersbach, Hans \\ Gete, Pedro \\ Gospodinov, Nikolay
}

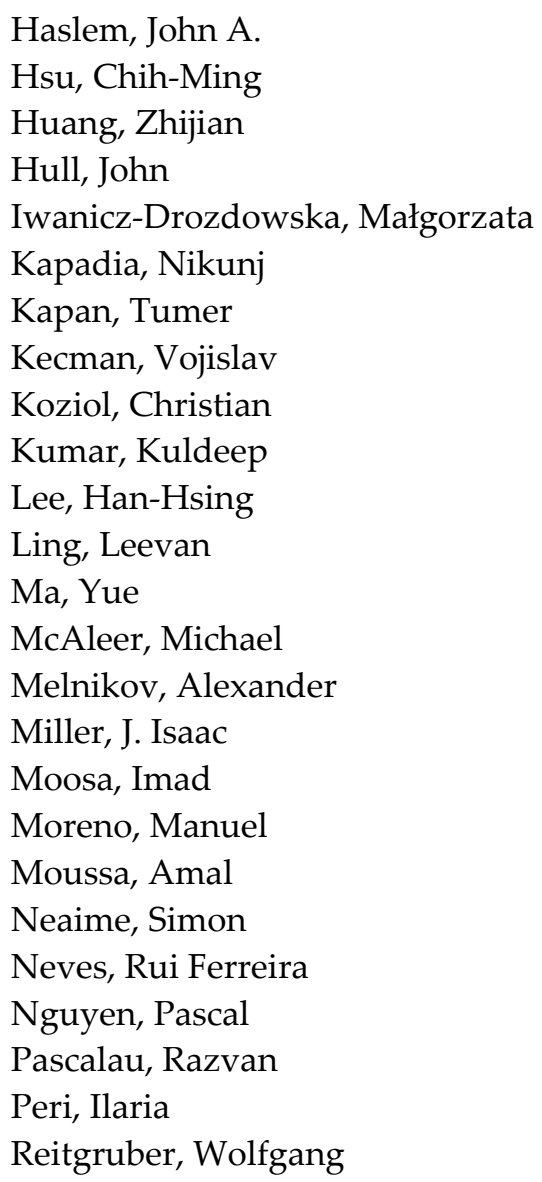


Sabal, Jaime

Schlütter, Sebastian

Spiegel, Matthew

Tasche, Dirk

Tchatoka, Firmin Doko

Tchistyi, Alexei
Tichý, Tomáš

$\mathrm{Wu}, \mathrm{Ji}$

$\mathrm{Xu}, \mathrm{Li}$

$\mathrm{Xu}$, Xiujuan

Zabarankin, Michael

Žikeš, Filip

(C) 2017 by the authors; licensee MDPI, Basel, Switzerland. This article is an open access article distributed under the terms and conditions of the Creative Commons Attribution (CC-BY) license (http://creativecommons.org/licenses/by/4.0/). 